\title{
Abschied von der manuellen Tonverarbeitung
}

\begin{abstract}
Im Designmodellbau findet derzeit ein grundlegender Paradigmenwechsel statt: Wo über hundert Jahre lang handwerkliches Geschick und Augenmaß den Ton angaben, werden bald weitgehend automatisierte Anlagen die Konditionierung und Verarbeitung von Tonmassen (Plastilin) übernehmen. Das Unternehmen Tartler bietet hierfür eine Systemlösung für die maschinelle Dosierung und Aufbringung an.
\end{abstract}

Seit ihrer Erfindung Ende des 19. Jahrhunderts setzen Modellbauer, Architekten und Künstler die per Hand knetbare Wachsmasse Plastilin zur manuellen Formgebung ein. Schon viele Jahre kommt dieser gemeinhin als Clay (engl. für Lehm, Ton) bezeichnete Werkstoff in großen Mengen auch in der Industrie - vorrangig im Automobilbau - zum Einsatz. Hier wurde er bis dato per Hand und mit einfachen Werkzeugen wie Spachteln aufgebracht und mit viel Fingerspitzengefühl modelliert. Gerade bei größeren Designobjekten im 1:1-Maßstab nimmt die thermische Konditionierung und das manuelle Auftragen der Grundmasse allerdings viel Personal und Zeit in Anspruch. Das Erwärmen von etwa $2 \mathrm{t}$ Ton in Form von Stangen und Brammen, die Entnahme des
Materials aus dem Ofen und seine grobe Applikation auf einen Unterbau beanspruchen meist mehrere Manntage. Die TonAuftragsmaschine bietet Modellbauern und Industriedesignern die Möglichkeit, Formenbau-Plastiline schnell und prozesssicher aufzutragen und die Bepastung und Gestaltung weitgehend halb- oder vollautomatisiert durchzuführen (Bild 1).

\section{Große Zeitersparnis}

Bei der Ton-Auftragsmaschine handelt es sich um eine Systemlösung bestehend aus einer manuellen oder automatischen Zuführung, einer temperierten Pumpeneinheit und einer Dosierleitung mit Applikationsdüse. Bedient wird die Anlage über eine

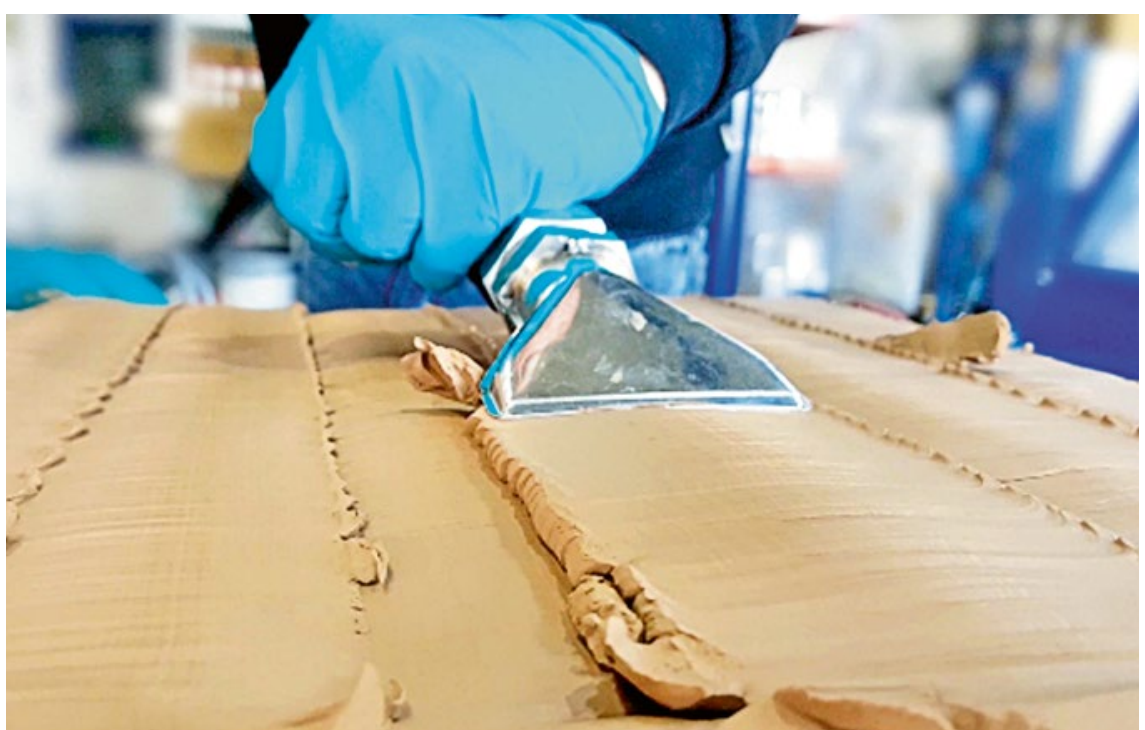

Bild 1 Im Vergleich mit bisher üblichen Methoden sparen Modellbauer und Industriedesigner Zeit, denn es können auch Breitstrahldüsen eingesetzt werden. (৫ Tartler)

\section{Produktvideo}

Ein erster Eindruck von der Arbeit des Systems kann in diesem Video gewonnen werden: clay.somata-gmbh.com.

Steuerung mit Touchscreen. Der Tonaustrag erfolgt sehr gleichmäßig, mit konstanter Materialtemperatur und mit einem Ausstoß von bis zu 1,2 kg/min. Zur Optimierung der Applikation lassen sich verschiedene Düsen einsetzen und die Ausstoßmenge kann individuell geregelt werden. Alle wichtigen Parameter des Applikationsprozesses werden protokolliert. Im Vergleich zu den bisher üblichen Methoden des Ton-Modeling wird Arbeitszeit gespart. Derzeit wird außerdem ein weiteres Modell mit einem Ausstoß von über $3,0 \mathrm{~kg} / \mathrm{min}$ entwickelt.

\section{Vollautomatisierung ist möglich}

Die Basisausführung wird als halbautomatisches und einfach bedienbares System bereitgestellt, das sich auch an Handlingvorrichtungen und Roboter anbinden lässt. Mit einer Anlage kann so manuell als auch vollautomatisch Ton aufgetragen werden. Die Schnittstellen dafür sind vorgesehen, eine automatisierte Nachfülleinheit ist bereits in Vorbereitung.

Kontakt:

Tartler Group, Michelstadt, www.tartler-group.com 